Indian Journal of Research in Pharmacy and Biotechnology

Volume 5, Issue 6, 2017

Journal homepage: http://www.ijrpb.com
ISSN:

2321-5674 (Print)

2320-3471

(Online)

Research article

Indexed in CAS and $\mathrm{CABI}$

Impact factor:0.64

\title{
Formulation And Evaluation Of The Prepared Floating Raft System Of Tizanidine HCL
}

\author{
Mahmoud M Omar ${ }^{1}$, Nermin E Eleraky² \\ ${ }^{1}$ Department of Pharmaceutics and Industrial Department, Deraya University, Minia 61768, Egypt \\ ${ }^{2}$ Department of Pharmaceutics, Faculty of Pharmacy, Assiut University, Assiut 71526, Egypt \\ *Corresponding author Email: mahmoudmomar@hotmail.com
}

Keywords:

Floating raft system;

Tizanidine $\mathrm{HCl}$;

Bioavailability

Enhancement.

Article Info:

Received: 27-11-2017

Revised: 21-12-2017

Accepted:26-12-2017

\section{ABSTRACT}

To extend the residence time of tizanidine $\mathrm{HCl}$ dosage form within the stomach until the drug released at the optimum rate for oral sustained-release drug delivery systems. Aim of the present study to develop a sustained-release floating raft system of tizanidine $\mathrm{HCl}$ to enhance its low bioavailability and overcome rapid metabolism. Physicochemical characteristics of tizinidine HCl FRS were evaluated. In addition, pharmacokinetics of the optimum, raft system formula, and marketed Sirdalud® $6 \mathrm{mg}$ sustained release as reference were examined in rabbits. The optimum floating raft (F9) was found to float within 27 seconds and remain buoyant for more than $24 \mathrm{~h}$ in simulated gastric fluid. All prepared raft system formulations showed sustained release, releasing about $60-80 \%$ of tizanidine $\mathrm{HCl}$ over 6 hours. The Cmax was 442 and $364 \mathrm{ng} / \mathrm{mL}$ for floating raft (F9) and marketed Sirdalud® 6mg, respectively. Moreover, relative bioavailability of the tizanidine $\mathrm{HCl}$ was $103.54 \%$ post oral administration of floating raft (F9), compared to marketed Sirdalud® 6 . These findings showed that the prepared sustained-release floating raft system would be promising drug delivery system for long acting action.

\section{INTRODUCTION}

Oral dosage forms are very important forms because of the patient compliance, administration ease, low risk of infection and masking of unpleasant taste. However, many factors such as; $\mathrm{pH}$ change along gastrointestinal tract (GIT) and gastric emptying time may lessen bioavailability of oral dosage forms when they are used.[1,2] To overcome low bioavailability, various novel pharmaceutical dosage forms were produced such as nano-suspensions,[3] colloid dispersions, and gastroretentive drug delivery systems.[4, 5] Gastroretentive drug delivery systems are classified into density-controlled delivery systems, bioadhesive systems and swellable systems. Density-controlled delivery systems have two types; floating systems which float and remains buoyant at the top of gastric liquid,[6] the highdensity systems are the dosage form which designed to be at the bottom of the stomach. The second type of gastroretentive drug delivery systems is bioadhesive system that bio-adhere to 
gastric mucosa.[7] The third type is swellable system that expands to too large size to pass to the duodenum.[8]

Floating systems are classified into effervescent and noneffervescent systems. The effervescent floating systems are prepared from swellable polymers such as chitosan and hydroxypropyl methylcellulose (HPMC) and various effervescent compounds such as citric acid and sodium bicarbonate. On other hand, noneffervescent systems are prepared from matrix-forming polymers such as polystyrene and polymethacrylate and gel forming cellulose.[9] Raft forming system is a type of gastroretentive delivery system. This system is initially a solution form, but when it comes into contact with stomach contents, a viscous cohesive gel is produced entrapping carbon dioxide that is generated when the sodium bicarbonate of formulation reacted with gastric hydrochloric acid leading to decrease the density of the gel.[10, 11] So, the formed gel has capability of floating above the gastric content for long time releasing its drug cargo.

Tizanidine $\mathrm{HCl}$ is anti-spasticity agent to reduce spasms that interferes with living activities.[12] Tizanidine $\mathrm{HCl}$ suffers from a short elimination half-life of $2.5 \mathrm{~h}$ and low bioavailability (34$40 \%$ ) as a result of extensive and rapid hepatic first-pass metabolism following oral administration.[13, 14] Frequent administration of tizanidine $\mathrm{HCl}$ is required causing poor compliance. Tizanidine $\mathrm{HCl}$ has been selected to be incorporated into floating raft system (FRS).

In evaluated the present study, floating raft systems (FRSs) used as a drug delivery system were for better control of tizanidine $\mathrm{HCl}$ release using different blends of both hydrophilic and lipid polymers. The optimum prepared FRS was evaluated for in vivo pharmacokinetics study compared to the commercial dosage form “Sirdalud ${ }^{\circledR}$ retard $6 \mathrm{mg}$-tablet"

\section{MATERIALS AND METHOD}

\section{MATERIALS}

Deacetylated gellan gum was supplied from Dainippon Pharmaceutical Co., Osaka, Japan. Tizanidine $\mathrm{HCl}(\mathrm{TIZ} \mathrm{HCl})$ was obtained as a gift from EIPICO, Egypt. A commercially available dosage form, Sirdalud ${ }^{\circledR} 6 \mathrm{mg}$ sustained-release capsule, (Reference), was purchased from Novartis, Cairo, Egypt. Kollicoat ${ }^{\circledR}$ SR 30 D (Polyvinyl acetate stabilized with polyvinylpyrrolidone and sodium lauryl sulfate), Precirol® ATO5 (glyceryl palmitostearate) and deacetylated gellan gum were purchased from Sigma-Aldrich, St Louis, MO, USA. Sodium citrate and sodium bicarbonate were purchased from (Adwic Pharmaceuticals, Cairo, Egypt). Methanol and formic acid high-performance liquid chromatography (HPLC) grade (Scharlau Chemie SA, Barcelona, Spain), sodium dihydrogen phosphate (Koch-Light Laboratories, Colnbrook Bucks, UK), ethyl acete amd hexan were all of pharmaceutical grade and used as received. 
Preparation Of Floating Dosage Forms of Tizanidine $\mathrm{HCl}$

\section{Coating of Drug with Kollicoat SR 30D}

TIZ $\mathrm{HCl}$ was dispersed homogenously in

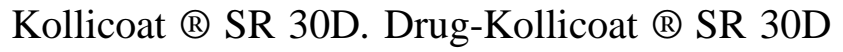
dispersion $(1: 1 \mathrm{w} / \mathrm{w})$ was dried at $60{ }^{\circ} \mathrm{C}$ for 1 hour. The dried dispersion of TIZ $\mathrm{HCl}(1: 1 \mathrm{w} / \mathrm{w})$ was kept in desiccator until further used in the raft preparations.

PREPARATION OF FLOATING RAFT SYSTEMS OF TIZANIDINE HCL

Nine gellan gum formulations with were prepared as reported in literature, with some modification,[15] as shown in Table (1). Briefly, gellan gum formulations were prepared by stirring proper amount of the gum into hot ultra-pure water $90^{\circ} \mathrm{C}$ containing $0.35 \% \mathrm{w} / \mathrm{v}(0.01356 \mathrm{~mol} / \mathrm{L})$ sodium citrate and 0.1 w/v $(0.01 \mathrm{~mol} / \mathrm{L})$ calcium carbonate. After cooling to below $40^{\circ} \mathrm{C}$, a proper amount of the coated TIZ was stirred well with a homogenizer (Homogenizer T-25; IKA, Staufen, Germany) at a speed of 2,000 rpm for 10 minutes. The prepared drug suspension was kept into amber bottles at $5 \pm 2{ }^{\circ} \mathrm{C}$

Table 1 Composition and physical characteristics of deacetylated gellan gum-based floating raft systems containing $\mathrm{HCl}$ at $6 \mathrm{mg} / 10 \mathrm{~mL}, 0.1 \% \mathrm{w} / \mathrm{v} \mathrm{CaCO}$, and $0.35 \% \mathrm{w} / \mathrm{v}$ sodium citrate

\begin{tabular}{|c|c|c|c|c|c|c|c|c|c|}
\hline $\begin{array}{c}\text { Formula } \\
\text { composition }\end{array}$ & $\begin{array}{c}\text { Deacetylated } \\
\text { gellan gum } \\
(\%, \mathrm{w} / \mathrm{v})\end{array}$ & $\begin{array}{c}\text { Kollicoat } \\
{ }^{\circ} \text { SR 30D } \\
(\%, \mathrm{w} / \mathrm{v})\end{array}$ & $\begin{array}{c}\text { Precirol } \\
(\%, \mathrm{w} / \mathrm{v})\end{array}$ & $\begin{array}{c}\text { Tizanidine } \\
\mathrm{HCl} \\
(\%, \mathrm{w} / \mathrm{v})\end{array}$ & Gelation & $\begin{array}{c}\text { Gelation } \\
\text { lag time } \\
(\mathrm{pH} \\
1.2)(\mathrm{sec})\end{array}$ & $\begin{array}{c}\text { Gelation } \\
\text { duration } \\
\text { time } \\
(\mathrm{h})\end{array}$ & $\begin{array}{c}\text { Floating } \\
\text { lag time } \\
(\mathrm{sec})\end{array}$ & $\begin{array}{c}\text { Duration } \\
\text { of } \\
\text { Floating } \\
(\mathrm{h})\end{array}$ \\
\hline F1 & 0.5 & 0.04 & $\mathrm{I}$ & 0.06 & + & 75 & 14 & 117 & 1.5 \\
\hline F2 & 0.5 & 0.06 & $\mathrm{I}$ & 0.06 & + & 62 & 14 & 97 & 2 \\
\hline F3 & 0.5 & 0.08 & $\mathrm{I}$ & 0.06 & + & 50 & 16 & $9 \mathrm{I}$ & 2.5 \\
\hline F4 & 1.0 & 0.04 & $\mathrm{I}$ & 0.06 & + & 48 & 22 & 85 & 4 \\
\hline F5 & 1.0 & 0.06 & $\mathrm{I}$ & 0.06 & ++ & $4 \mathrm{I}$ & 24 & 72 & 7 \\
\hline F6 & 1.0 & 0.08 & $\mathrm{I}$ & 0.06 & ++ & 35 & 24 & 58 & 9 \\
\hline F7 & 1.5 & 0.04 & $\mathrm{I}$ & 0.06 & ++ & 20 & 34 & 47 & 12 \\
\hline F8 & 1.5 & 0.06 & $\mathrm{I}$ & 0.06 & +++ & 12 & 34 & 36 & 12 \\
\hline F9 & 1.5 & 0.08 & $\mathrm{I}$ & 0.06 & +++ & 9 & 36 & 27 & 24 \\
\hline
\end{tabular}

Notes: $(-)$, no gelation; $(+)$, weak gelation; $(++)$, good gelation; $(+++)$, very good gelation

In Vitro Evaluation Of Physicochemical Characteristics Of Tizinidine HCL FRS

\section{MEASUREMENT OF VISCOSITY}

Viscosity measurements were carried out using a viscometer, (Brookfield, Engineering laboratories, Inc., Stoughton, MA 02072 USA).

The study was achieved at different angular velocities at $25{ }^{\circ} \mathrm{C} \pm 1^{\circ} \mathrm{C}$. Angular velocity was increased from 10 to $100 \mathrm{rpm}$ at each run. The viscosity ( ) in centipoise and shear rate in s-1 were measured using a rotating viscometer. The flow index (n) and the consistency index (m) are characteristics for each formulation.

$\eta=m r^{n-1}$

Equation (1)

Where Newtonian behavior of formulation is proved when the flow index equals one. However, non- Newtonian behavior of formulation is 
proved when the flow index equals less than one.

All determinations are average of three replicates.

The lower the value of $\mathrm{n}$, the more shear thinning is characterizing the formulation. The higher value of consistency index $(\mathrm{m})$ in the prepared gel may exert substantial contribution to the shear viscosity of the gel.[16]

\section{IN VITRO GELATION STUDY}

Capacity of gelation was determined by slowly pouring $5 \mathrm{~mL}$ of the formulation into a beaker containing simulated gastric SG fluid $\mathrm{pH}$ 1.2. [17] The formed gel was visually examined, where gelation-lag time and gelation duration were determined. Strength for the prepared gel formulations was assessed

qualitatively by pressing sample of gel with fine forceps.[18]

\section{IN VITRO BUOYANCY STUDY}

The examination was carried out to determine floating lag time and floating duration for each one of formulae. The examination was carried out by slowly immersing watch glass containing $10 \mathrm{~mL}$ of each the prepared raft system in a dissolution cup containing $500 \mathrm{~mL}$ of SG fluid. The system was thermostatted at $37^{\circ} \mathrm{C} \pm 0.5^{\circ} \mathrm{C}$ in a water bath. The time period required for floating of dosage form (floating lag time), and time during which the formulations remains floating (duration of floating) were determined.[19] All measurements were average of three replicates.
In-Vitro Release of Tizanidine $\mathrm{HCl}$ from Floating Raft System

Dissolution studies of the formulae were achieved using USP dissolution test apparatus II (USP 24). The dissolution medium (900 mL, $\mathrm{pH}$ 1.2, simulated gastric fluid) was heated to $37^{\circ} \mathrm{C}$ $\pm 0.5^{\circ} \mathrm{C}$ and rotation of paddle was adjusted at 50 rpm.[20, 21] In the dissolution vessel, $10 \mathrm{~mL}$ of floating raft system was slowly poured off. Aliquots of dissolution medium $(5 \mathrm{~mL})$ were taken at prespecified time intervals along 12 hours, replaced with $5 \mathrm{~mL}$ of fresh prepared simulated gastric fluid SGF, filtered and assayed using spectrophotometer (UV-1601; Shimadzu, Kyoto, Japan) at $228 \mathrm{~nm}$. All measurements were determined triplicate and mean values were plotted (mean $\pm \mathrm{SD}$ ). All measurements were treated with different models; zero-order, firstorder, Higuchi, Hixon-Crowell, Peppas, and Weibull kinetic equations.[21] The determination coefficient (R2) of each model was determined, the highest one was considered to best fitting one.[22] The model with the highest coefficient of determination (R2) was believed to be the best fitting one.[23]

\section{STATISTICAL ANALYSIS}

Results were statistically analyzed using the software SPSS 17.0 (SPSS Inc., Chicago, IL, USA). One-way analysis of variance (ANOVA) was applied followed with Tukey Kramer multiple assessments for pairwise comparison (GraphPad Prism 6.0, GraphPad, San Diego, CA, USA). The calculated differences between 
formulations were considered to be significant at $\mathrm{P}<0.05$.

\section{Preparation Of Animals}

\section{Animals}

Male New Zealand rabbits were provided by the animal hospital of the Faculty of veterinary Medicine, Assiut University. They were kept at standard condition $\left(25^{\circ} \mathrm{C} \pm 1^{\circ} \mathrm{C}, 40 \% \mathrm{RH}\right)$. The experiment steps were accepted by the Committee of Animal Ethical in the Faculty of Medicine, Assiut University. All procedures of animal experiments were achieved in accordance with the UK Animals (Scientific Procedures) Act, 1986 and associated guidelines, EU Directive 2010/63/EU for animal experiments. Within the present study, eighteen adult New Zealand rabbits were provided by the animal hospital Faculty of Veterinary Medicine at Assiut University. The rabbits were randomly divided into six groups $(n=3)$, with each group including three rabbits. Rabbits received orally the following formulations: F9 and sustained-release tizanidine marketed product "Sirdalaud $\AA$ SR $6 \mathrm{mg}$ tablet were used throughout the study.

\section{Application Technique}

For the first group $(\mathrm{n}=3), 10 \mathrm{~mL}$ of the formula F5 (equivalent to $6 \mathrm{mg}$ tizanidine $\mathrm{HCl}$ ) was given orally. In the second group, $10 \mathrm{~mL}$ of the formula F6 was given orally. For the first, the second, the third and the fourth group $(\mathrm{n}=3), 10 \mathrm{~mL}$ of the formula F11 and F12 (equivalent to $6 \mathrm{mg}$ tizanidine $\mathrm{HCl}$ ) were given orally, respectively. For the fifth group, the market product "Sirdalud
(- - 6 mg" (retard-release tizanidine tablet) was given orally (Fifth group). Rabbits of control group were not given any thing, only water was permitted to be taken. Blood samples $(5 \mathrm{~mL})$ were collected from ear vein at 0, 0.5, 1, 2, 4, 8, 10, 12 and $24 \mathrm{~h}$ after dose taking. The plasma samples were obtained by centrifuging the collected blood samples, at $3000 \mathrm{rpm}$ for 10 minutes. The obtained plasma was stored at -20 ${ }^{\circ} \mathrm{C}$ until they were analyzed by HPLC.[24]

\section{Chromatographic System}

\section{Samples Preparation For Analysis}

\section{Processing Of Biosamples}

A $100 \mu \mathrm{L}$ of tolterodine (as internal drug) was vortexed with $500 \mu \mathrm{L}$ of the obtained plasma biosamples for 1 minute. The mixtures were vortexed with $5 \mathrm{~mL}$ of ethyl acete: hexan (90:10 $\mathrm{v} / \mathrm{v}$ ) mixture at $4000 \mathrm{rpm}$ for 5 minutes. Then, the organic layer was poured off into a clean tube. Dry residue was obtained by evaporation of organic layer under vacuum at $40^{\circ} \mathrm{C}$. Finally, reconstitution of dry residue was carried out with $150 \mathrm{~mL}$ mobile phase (methanol: 0.1 formic acid 80: $20 \mathrm{v} / \mathrm{v}$ ). For analysis, a $5 \mu \mathrm{L}$ of reconstituted solution was injected on the column. The analysis was performed using a reproducible, sensitive and accurate liquid chromatography-tandem mass spectroscopy (LC-MS/MS) method. The chromatographic separation was carried out on akinetex C18column 50X4.6mm and particle size of $2.6 \mathrm{~m}$ (Phenomenex Inc., Torrance, CA). The flow rate was adjusted to $0.6 \mathrm{ml} / \mathrm{min}$. The analysis was performed at the MRM (multiple reaction 
monitoring) mode. The ion spray voltage was adjusted at $3000 \mathrm{~V}$. The analysis was performed at the multiple reaction monitoring (MRM) mode, and its MS parameters were as follows: precursor ion (Da) was 254.1 and 326.5 for TIZ and tolterodine, respectively, whereas product ion (Da) was 44.2 and 147.2 for TIZ and tolterodine, respectively.[25-27]

A Calibration Curve of TIZ in Plasma was Conducted Over The Range of 0.1-200 ng/ml.

\section{PHARMACOKINETIC ANALYSIS}

Profiles of plasma concentrations (the mean \pm standard deviation) versus time were constructed to calculate pharmacokinetic parameters. A twocompartment open model was applied using winLIN 3.2 software package (Colo-Parmer Co. Ltd.). The maximum plasma concentration (Cmax), the time required to reach the maximum plasma concentration (Tmax) and also the time required tizanidine to be estimated in plasma (Tlag) were directly estimated. The terminal part of plasma concentration profile was used to estimate Kel. Hence, Half-life time of elimination was calculated as follows:

Profiles of plasma concentrations (the mean \pm standard deviation) versus time were constructed to calculate pharmacokinetic parameters. A twocompartment open model was applied using winLIN 3.2 software package (Colo-Parmer Co. Ltd.). The maximum plasma concentration (Cmax), the time required to reach the maximum plasma concentration (Tmax) and also the time required tizanidine to be estimated in plasma
(Tlag) were directly estimated. The terminal part of plasma concentration profile was used to estimate Kel. Hence, Half-life time of elimination was calculated as follows:

$$
\mathrm{t}_{1 / 2}=0.693 / \mathrm{k}
$$

The extent of absorption was represented by area under the curve (AUC). So, the area under the curve (from 0 to $24 \mathrm{~h}$ ) was calculated by trapezoidal rule method. While the area under the curve to infinity $(\mathrm{A} 0-\infty)$ was calculated as follows:

$$
\mathrm{AUC}_{0-\infty}=\mathrm{AUC}_{0-\mathrm{t}}+\mathrm{C}_{\mathrm{t}} / \mathrm{K}_{\mathrm{el}} \quad \text { Equation (1) }
$$

The relative bioavailability $(\mathrm{F})$ of were calculated considering the market product as reference, as follows: $\mathrm{F}=\mathrm{AUC}_{\text {test }} / \mathrm{AUC}_{\mathrm{ref}} \times 100$

\section{Statistical Evaluation Of The Results}

All experiments were carried out in triplicate. The differences were evaluated for statistical significance using Student's t-test. A one-way analysis of variance (ANOVA) was used to the difference between the mean pharmacokinetic parameters estimated after administration of each of the three administrations into each rabbit group.

\section{Results And Discussion}

Assessment Of Floating Raft Systems FRS for Delivery Of Tizanidine $\mathbf{H C l}$

Physicochemical Characters of FRS of Tizanidine $\mathrm{HCl}$

The optimum viscosity of the formulated liquid sol, gelation (rate and extent of gelation) and floating 
(rate and floating duration) are important parameters for producing floating raft system. Viscosity of the optimum FRS should be at a value, permitting easy swallowing as a liquid form. However, the liquid form should transit to floating gel form because of ionic interaction. Moreover, the formed gel should be characterized by stable floatation and integrity for significant period, allowing extended release of the drug, without dissolving or eroding the system.

Gelation of $\mathrm{G}$ gum polymer takes place as result to the presence of either divalent or monovalent cations in the dissolution medium. The gelation mechanism explaining in-sol to gel transition by these polymers had been reported by many authors.[28] Those polymers present as double helix in ions free medium at $25^{\circ} \mathrm{C}$, as result of Van der waals interaction between two helix is carried out. Viscosity of those polymer solutions is close to that of water. The ingredients of the prepared formulations are shown in Table 1. A physical inspection of the formulae showed that those formulations were liquid upon storage and could not make any obstacle for swallowing. Promoting gelation of polysaccharides depends on presence of cations, but divalent cations like calcium are more powerful in gellation than monovalent cations like sodium.[29, 30] Consequently, calcium carbonate was used in our study to provide the medium with calcium ions and carbon dioxide gas needed for buoyancy of the prepared tizanidine $\mathrm{HCl}$ raft systems. Both free calcium ions and carbon dioxide gas were liberated as soon as calcium carbonate-raft system was in contact with acidic medium. Free calcium ions contribute in gelation of polysaccharide and construction of network. Liberated carbon dioxide gas was entrapped within the gel network; consequently the floatation of the raft system was occurred either on acidic dissolution medium or on gastric medium. Sodium citrate $(0.25 \% \mathrm{w} / \mathrm{v})$ was incorporated into FRS to inhibit premature gelling of the dosage form during storage. Where sodium citrate entraps free calcium ions by complexation and only allows calcium being free ion in acidic medium. The optimum concentration of sodium citrate was appointed in many literatures.[31]

Assessment of Gellan Gum-Based FRSs for Delivery Of Tizinidine $\mathrm{HCl}$

Our studies showed that all concentrations of gellan gum $(0.5,1$ and $1.5 \% \mathrm{w} / \mathrm{v}, 1 \% \mathrm{w} / \mathrm{v} \mathrm{CaCO} 3)$ preparations were easy to be poured and passed the floating and gelation evaluation, but integrity of the formed gel retained for hours ranging from 1 to < $24 \mathrm{~h}$ (Table 2). The gelling characteristics of FRSs are important to be administered orally. Concentration of the used polymer is also very important, where the concentration is high for forming gel with optimum strength and also it is low for forming gel with optimum viscosity for ease of swallowing.

HPMC K50 M was utilized in formulating the formulae to enhance the gelation capacity of gellan, and also as sustained-release materials, while amphiphilic lipid (Lauroglycol ${ }^{\mathrm{TM}}$ 90) was added to the formulations to retard drug release efficiently. 
Table (2): Flow behavior and viscosity parameter of gellan gum-based FRSs containing $\mathrm{Tz} \mathrm{HCl}$ as $6 \mathrm{mg} / 10 \mathrm{ml}$ and $0.25 \% \mathrm{w} / \mathrm{v}$ sodium citrate.

\begin{tabular}{|l|l|l|l|l|}
\hline \multirow{2}{*}{ Formula } & \multicolumn{2}{|c|}{ Viscosity parameter } & \multirow{2}{*}{ Viscosity of sols (cps) } & \multicolumn{1}{|c|}{ Flow behavior } \\
\cline { 2 - 3 } & Flow index (y) & $\begin{array}{c}\text { Consistency } \\
\text { index (m) }\end{array}$ & & \\
\hline F1 & 0.874 & $0.26 * 10 \mathrm{e}^{3}$ & 305 & Shear thinning \\
\hline F2 & 0.845 & $0.47 * 10 \mathrm{e}^{3}$ & 651 & Shear thinning \\
\hline F3 & 0.806 & $0.65 * 10 \mathrm{e}^{3}$ & 723 & Shear thinning \\
\hline F4 & 0.751 & $0.38 * 10 \mathrm{e}^{3}$ & 962 & Shear thinning \\
\hline F5 & 0.613 & $0.21 * 10 \mathrm{e}^{4}$ & 912 & Shear thinning \\
\hline F6 & 0.553 & $0.27 * 10 \mathrm{e}^{4}$ & 1896 & Shear thinning \\
\hline F7 & 0.328 & $0.59 * 10 \mathrm{e}^{4}$ & 4089 & Shear thinning \\
\hline F8 & 0.282 & $0.64 * 10 \mathrm{e}^{4}$ & 4351 & Shear thinning \\
\hline F9 & 0.302 & $0.58 * 10 \mathrm{e}^{5}$ & 4021 & Shear thinning \\
\hline
\end{tabular}

As shown in Table (2), concentration of polymer affected the viscosity of the formulations, where increase of the polymer concentration from 0.5 to $1.5 \%$ led to improve their consistency more than 11 folds. All formulations were characterized with shear thinning behavior. These findings agreed with results obtained with Miyazaki et al.[32] The results can be explained on basis chain interaction increase and entanglement among polymer chains.

Incorporation deacetylated gellan gum, Kollicoat ${ }^{\circledR}$ SR 30D and lipid (Precirol) led to increase the viscosity. The highest viscosity (4351 cp at $40 \mathrm{rpm}$ ) was observed with the formulation F9 (deacetylated gellan gum $1.5 \%$, Kollicoat ${ }^{\circledR}$ SR 30D $0.08 \%$, Precirol $1 \%)$, while the formulation F1 (deacetylated gellan gum $0.5 \%$, Kollicoat ${ }^{\circledR}$ SR 30D $0.04 \%$, Precirol $1 \%$ ) showed the lowest viscosity
(305 cp at 40 r.p.m). Decrease of viscosity led to lack of homogeneity of drug dispersion; hence uniformity of drug content was lost. Accordingly, the formulation F9, (deacetylated gellan gum 1.5\%, Kollicoat ${ }^{\circledR}$ SR 30D 0.08\%, Precirol 1\%) was chosen for further examinations.

\section{In Vitro Gelation Study}

This study was conducted in SGF (0.1N HCl, pH 1.2). Rapid gelation was observed with all formulations except F1and F4. As the concentration of gellan increased (from $0.5 \%, 1 \%$ and finally to $1.5 \%$ ), the gelation capacity and gel strength increased while the gelation time decreased. 
Weak gels were formed by the prepared formulations (F1and F4) with low content of gellan. Hence, the formed gels dissolved rapidly within 1.5 and $2.8 \mathrm{~h}$, respectively. As result of the weakness of the formed gel, these formulations (F1 and F4) will be transferred to duodenum by the peristaltic movements, so they are not suitable for taking as oral dosage forms.[33] However, the formulations (F8 and F9) with high content of gellan polymer formed strong gel leaving clear solution. The formed gels lasted for more than $24 \mathrm{~h}$. Increase gellan concentration to $1.5 \%$ and incorporation of HPMC K50M resulted in adequate gel strength. The formed gels (F8 and F9) showed adequate gel strength when they were examined using a pair of fine forceps to press on the gel simulating what it is $F 2=101 \mathrm{~s}, F 5=83 \mathrm{~s}, F 8=49 \mathrm{~s})$ and also from (F3=95s, $F 6=78 s, F 9=37 s)$. These findings can be elucidated on basis of increase of gel viscosity as a result of increase of percent amount of deacetylated gellan gum. Moreover, regardless of increase of deacetylated gellan gum, increase of Kollicoat ${ }^{\circledR}$ SR $30 \mathrm{D}$ led to increase of floating duration and decrease of floating lag time as shown in formulae (F1-F3), (F4-F6) and (F7-F9). Furthermore, low permeability of the produced gel, as a result of an increase the viscosity, inhibited loss of entrapped carbon dioxide, enhancing floating efficiency. These results are concurrent with a published study [27] however, these results are nonconcurrent with other study.[27]. encountered in the stomach. Lipid incorporation into the prepared raft system enhances gelation capacity as shown in Table 2.

\section{In Vitro Floating Properties Of FRS}

As shown in Table (1), enhanced gelation capacity was observed as result of increase of deacetylated gellan gum and Kollicoat ${ }^{\circ}$ SR 30D into through formulations. Enhanced gelation was demonstrated by both decrease lag time of gelation and increase of gelation duration from $1.5 \mathrm{~h}$ to $36 \mathrm{~h}$. Floating duration was enhanced by increasing percent amount of deacetylated gellan gum and Kollicoat ${ }^{\circledR}$ SR 30D. However, floating lag time decreased from $(\mathrm{F} 1=122, \mathrm{~F} 4=104 \mathrm{~s}, \mathrm{~F} 7=55 \mathrm{~s}),($

\section{In-Vitro Release Of The Prepared Floating Raft System Of Tizanidine HCl}

In the present study, floating raft systems were prepared from different blends containing deacetylated gellan gum, Kollicoat ${ }^{\circledR}$ SR 30Dand precirol. Deacetylated gellan gum was used in three different levels $(0.5,1$ and $1.5 \% \mathrm{w} / \mathrm{v})$. Kollicoat ${ }^{\circledR}$ SR 30D was utilized in three different concentrations $(0.04,0.06$ and $0.08 \%$ w/v). Moreover, Precirol was also utilized in only one concentration $(1 \% \mathrm{w} / \mathrm{v})$. Hence, nine floating raft systems (F1-F9) were formulated and utilized by these variations of ingredients, as shown in Table 


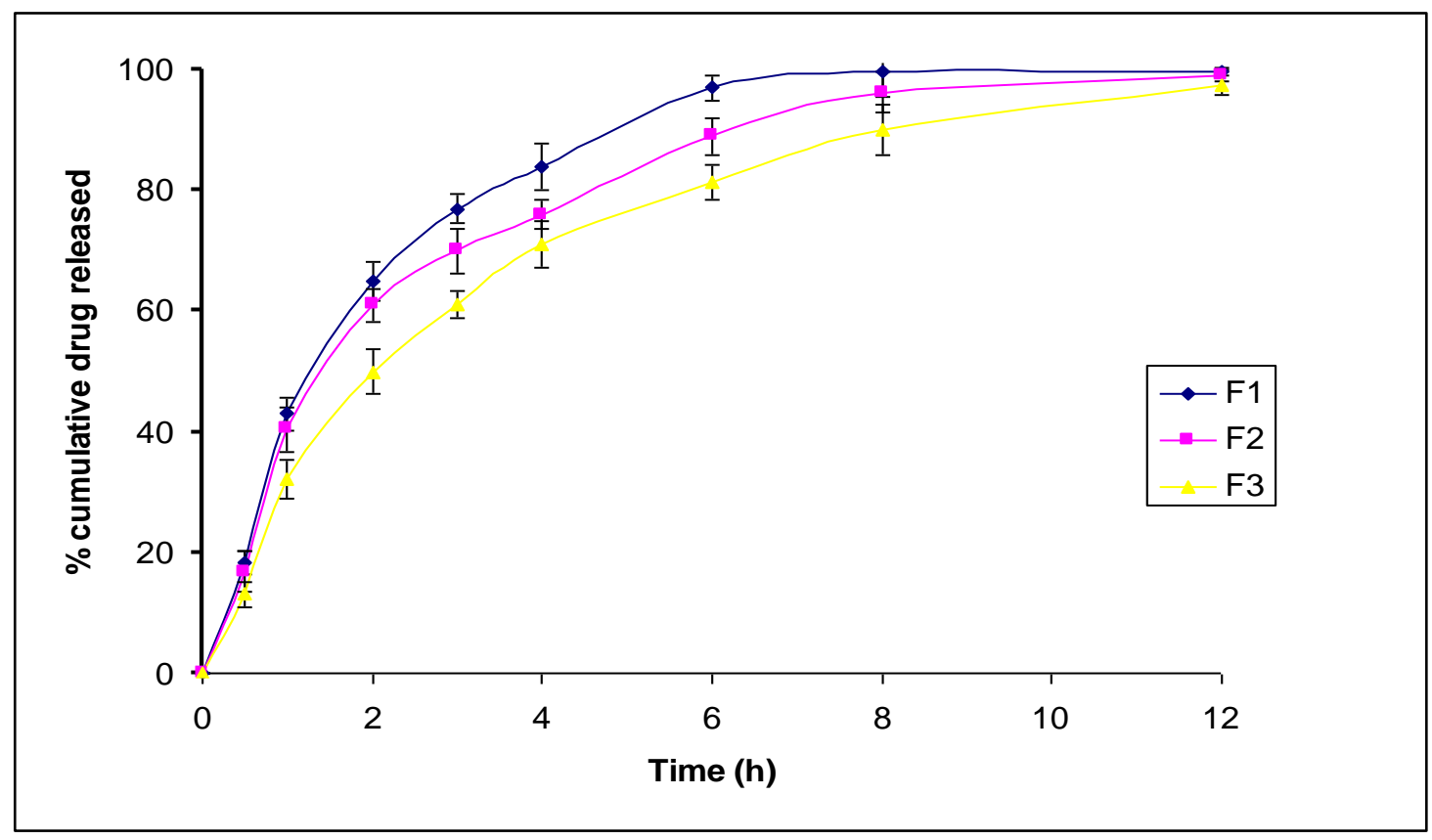

Figure (1): In vitro dissolution profile from deacetylated gellan gum $(0.5 \mathrm{w} / \mathrm{v} \%)$ based floating raft dosage forms with various concentrations of Kollicoat ${ }^{\circledR}$ SR 30D (0.04, 0.06 and 0.08\%) and lipid polymer Precirol $(1 \%), \quad\left(\mathrm{pH}=1.2\right.$, at $37^{\circ} \mathrm{C}$ dissolution medium $)$ 


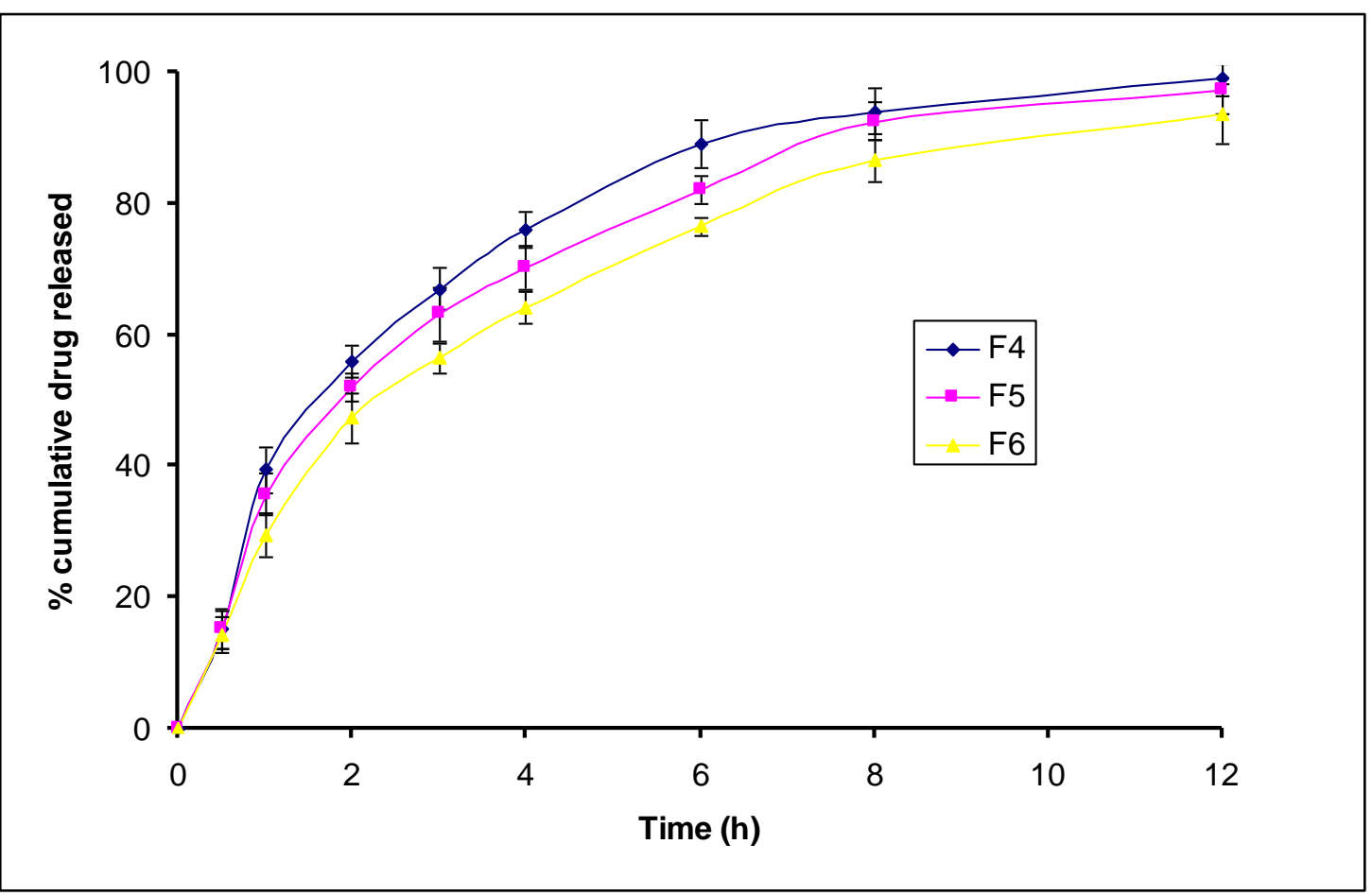

Figure (2): In vitro dissolution profile from deacetylated gellan gum (1 w/v \%) based floating raft dosage forms with various concentrations of Kollicoat ${ }^{\circledR}$ SR 30D (0.04, 0.06 and 0.08\%) and lipid polymer; Precirol $(1 \%),\left(\mathrm{pH}=1.2\right.$, at $37^{\circ} \mathrm{C}$ dissolution medium).

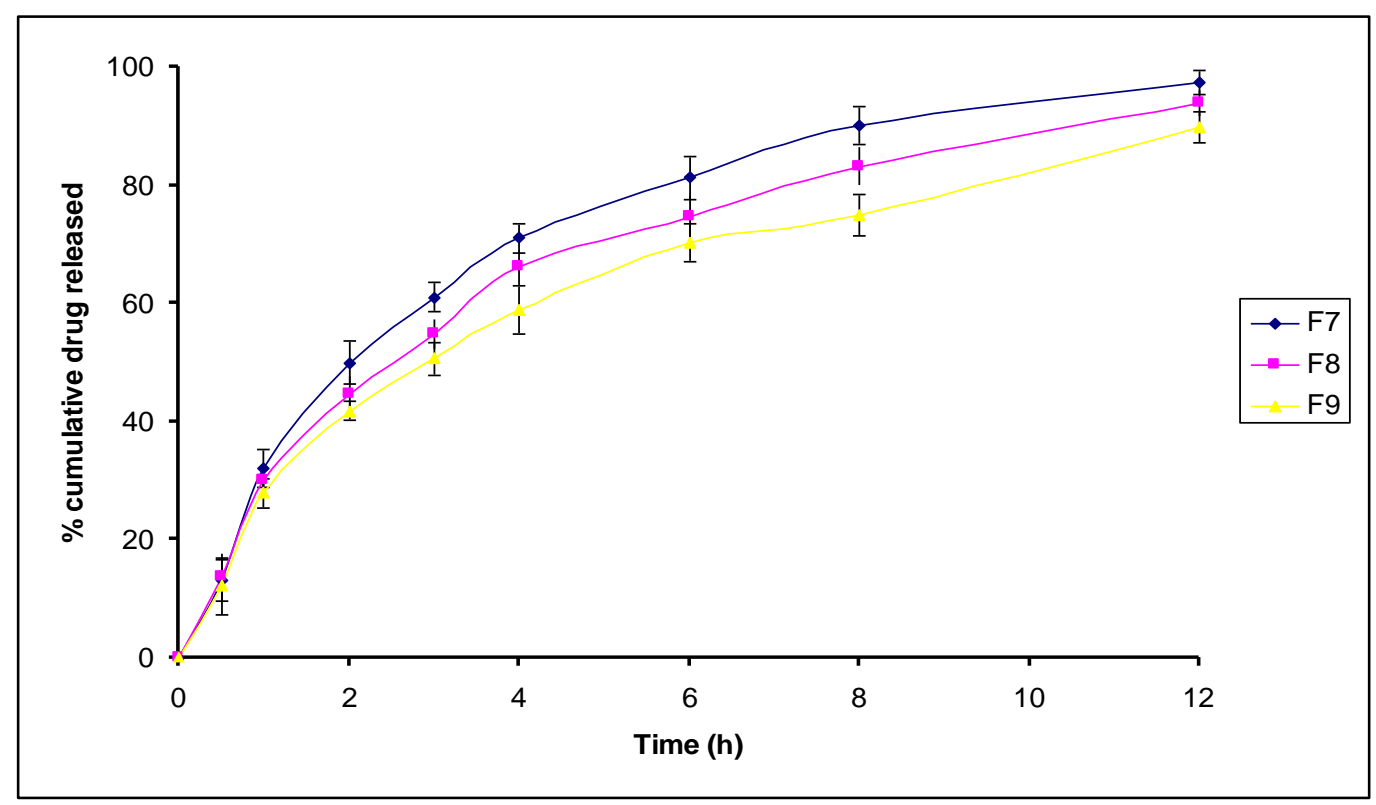

Figure (3): In vitro dissolution profile from deacetylated gellan gum $(1.5 \mathrm{w} / \mathrm{v} \%)$ based floating raft dosage forms with various concentrations of Kollicoat ${ }^{\circledR}$ SR 30D (0.04, 0.06 and 0.08\%) and lipid polymer; Precirol $(1 \%),\left(\mathrm{pH}=1.2\right.$, at $37^{\circ} \mathrm{C}$ dissolution medium $)$ 
The release of tizanidine $\mathrm{HCl}$ from the deacetylated gellan gum floating raft systems is represented in Figures 1, 2 and 3.

A significant lowering $(\mathrm{P}<0.05)$ in the percentage of cumulative drug released was recorded with the increase in deacetylated gellan gum levels from 0.5 to $1.5 \mathrm{w} / \mathrm{v} \%$, which may be explained on the basis of the density of polymer matrix. Moreover, increase of length of diffusional path that the drug should pass may be a great impact on sustaining the release of drug.

Formulations prepared of kollicoat@ SR 30D at concentration $0.02 \%$ w/v (F1, F4 and F7) show the lowest drug release when F1 was compared with either F2 or F3, and when F4 was compared with either F5 or F6, and finally when F7 was compared with either F8 or F9, as shown in Figures 1-3. These results could be elucidated on the basis of synergistic effect of kollicoat@ SR 30D polymer to enhance the resultant systems. Precirol was incorporated at level $1 \% \mathrm{w} / \mathrm{v}$ in deacetylated gellan gum $(1.5 \mathrm{w} / \mathrm{v} \%)$ based floating raft dosage forms. The goal of precirol incorporation at level $1 \% \mathrm{w} / \mathrm{v}$ in deacetylated gellan gum $(1.5 \mathrm{w} / \mathrm{v} \%)$ based floating raft dosage forms was to retard tizanidine $\mathrm{HCl}$ release significantly, compared with the deacetylated gellan gum $(1.5 \mathrm{w} / \mathrm{v} \%)$ based floating raft dosage forms with precirol at level $0 \% \mathrm{w} / \mathrm{v}$ (Supplementary data). Precirol $(1 \% \mathrm{w} / \mathrm{w})$ was incorporated for optimizing release rate of the tizanidine $\mathrm{HCl}$. Reported literature emphasized that precirol has significant effect release rate of the drug from floating raft systems.[34] These results could be elucidated on basis of HLB (hydrophilic lipophilic balance) of precirol. Where the lower HLB value was, the lower release of the drug was recorded because of transforming into a cubic phase in gastric fluid; whereas the cubic phase is one of three formed phases; the first one is lamellar and the second one is amphiphillic reversed hexagonal and finally, the cubic phase is the last one. As water content of gastric fluid increase, the cubic phase is formed leading to form the high viscous and stiffness of the formed phase.[4]

\section{KINETICS OF RELEASE}

Various model-dependent approaches such as Higuchi model, Korsmeyer-Peppas model, and Hixson-Crowell model in addition to zero order and first order, were utilized to treat the in vitro release data of the formulations (F1-F9), as presented in Table (3). The most suitable model was chosen on basis of best fitting that was indicated by the correlation coefficient value (R2) nearer to 1.[27]

Concerning F1-F9, the highest correlation coefficient values R2 were calculated after fitting the in vitro release data into Higuchi equation. These findings indicate a Higuchi diffusion mechanism and that drug release was governed by diffusion.[35] 
Table (3): Kinetic treatment of in vitro release results of Tizanidine $\mathrm{HCl}$ that collected from floating raft systems F1-F9

\begin{tabular}{|c|c|c|c|c|c|c|}
\hline \multirow{2}{*}{ Formulations } & \multirow{2}{*}{$\begin{array}{l}\text { Zero- model } \\
\qquad \mathrm{R}^{2}\end{array}$} & \multirow{2}{*}{$\begin{array}{c}\text { First- model } \\
\qquad \mathrm{R}^{2}\end{array}$} & \multirow{2}{*}{$\begin{array}{l}\text { Higuchi- } \\
\text { model } \mathrm{R}^{2}\end{array}$} & \multicolumn{2}{|c|}{ Korsmeyer-peppas model } & \multirow{2}{*}{$\begin{array}{l}\text { Hixon- } \\
\text { crowell } \\
\text { model } \mathrm{R}^{2}\end{array}$} \\
\hline & & & & $\mathrm{R}^{2}$ & $\mathrm{n}$ & \\
\hline F1 & 0.855454 & 0.975572 & 0.988993 & 0.869626 & 0.508363 & 0.986708 \\
\hline $\mathrm{F} 2$ & 0.856233 & 0.907887 & 0.99105 & 0.887434 & 0.508363 & 0.986708 \\
\hline F3 & 0.870525 & 0.994223 & 0.991721 & 0.920307 & 0.600533 & 0.966083 \\
\hline $\mathrm{F} 4$ & 0.848346 & 0.9722 & 0.988951 & 0.891294 & 0.551437 & 0.966083 \\
\hline F5 & 0.86908 & 0.988278 & 0.993571 & 0.920427 & 0.555907 & 0.96198 \\
\hline F6 & 0.913471 & 0.963907 & 0.995995 & 0.94856 & 0.576915 & 0.965839 \\
\hline F7 & 0.873179 & 0.995146 & 0.991781 & 0.920307 & 0.600533 & 0.968598 \\
\hline F8 & 0.879346 & 0.987176 & 0.993216 & 0.945655 & 0.581369 & 0.96071 \\
\hline F9 & 0.87194 & 0.970029 & 0.992427 & 0.944264 & 0.591842 & 0.962278 \\
\hline
\end{tabular}

Notes: R2; regression coefficient, $\mathrm{n}$; release exponent

\section{PHARMACOKINETIC STUDY}

A pharmacokinetic study of the selected in situ raft system (F9) of tizanidine $\mathrm{HCl}$ compared with commercial product of tizanidine $\mathrm{HCl}$ product (Sirdalud® retard $6 \mathrm{mg}$ ) was carried out following oral intake of $6 \mathrm{mg}$ of the drug in beagle rabbits. The plasma concentration-time profile for the FRS (F9) and commercial product of tizanidine $\mathrm{HCl}$ product (Sirdalud ${ }^{\circledR}$ retard $6 \mathrm{mg}$ ) were represented in Figure 4. The pharmacokinetic parameters were listed in Table 4. 


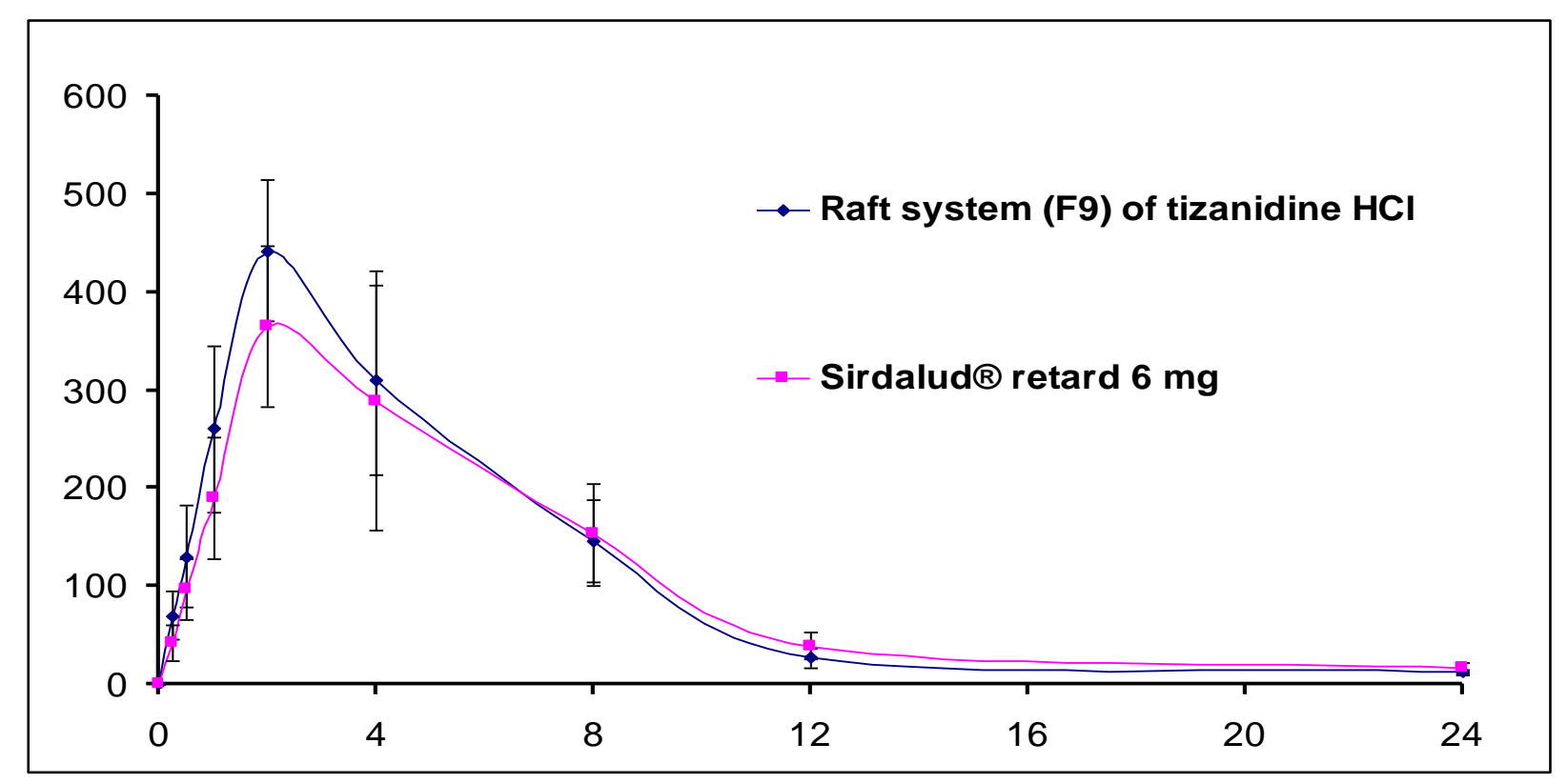

Figure (4): Plasma concentration of Tizanidine $\mathrm{HCl}$ following oral administration of the prepared raft system (F9) and market dosage form (Sirdalud ${ }^{\circledR}$ retard $6 \mathrm{mg}$ ) to rabbit.

Note: Each point represents mean $\pm \mathrm{SE}(\mathrm{n}=3)$.

Findings showed that after oral administration of floating raft system F9 and market dosage form to rabbits, the drug was detected in plasma after $0.25 \pm 0.15 \mathrm{~h}$, and $0.81 \pm 0.31 \mathrm{~h}$, respectively, as represented in Table (4). Mean maximum tizanidine $\mathrm{HCl}$ plasma concentration of F9, Cmax (442 \pm 70 $\mathrm{ng} / \mathrm{mL}$ ) was higher than that of the commercial product of tizanidine $\mathrm{HCl}$ product (Sirdalud® retard $6 \mathrm{mg})(362 \pm 82 \mathrm{ng} / \mathrm{mL})$. The mean time (Tmax) of both tested formulae that maximum concentration was attained, were compared. There is insignificant difference $(\mathrm{P}>0.05)$ between Tmax of floating raft system (F9) and the market dosage form "Sirdalud $\AA$ retard $6 \mathrm{mg}$ ". 
Table (4): Pharmacokinetic parameters of tizanidine $\mathrm{HCl}$ in rabbit plasma following administration of Floating raft system (F9), and the market dosage form Sirdalud ${ }^{\circledR}$ retard $6 \mathrm{mg}$-tablet

\begin{tabular}{|c|c|c|}
\hline \multirow{2}{*}{ Pharmacokinetic parameters } & \multicolumn{2}{|l|}{ Formula } \\
\hline & Floating raft system (F9) & Sirdalud $®$ retard 6 mg -tablet \\
\hline$C_{\max }(n g / m L)$ & 442 & 364 \\
\hline $\mathbf{T}_{\max }(\mathbf{h})$ & 2 & 2 \\
\hline Kel & 0.14854 & 0.19737 \\
\hline $\mathbf{t}_{1 / 2}(\mathbf{h})$ & 4.665 & 3.511 \\
\hline $\operatorname{AUC}_{0-12}(\mathrm{ng} \mathrm{h} / \mathrm{mL})$ & 1313.438 & 1363.125 \\
\hline $\operatorname{AUC}_{\mathbf{0}-\infty}(\mathbf{n g} \mathbf{h} / \mathbf{m L})$ & 1443.909 & 1394.505 \\
\hline $\mathrm{F}_{\text {rel }}(\%)$ & 103.54 & 100 \\
\hline
\end{tabular}

The terminal elimination rate constant of Floating raft system (F9) was not significantly different ( $>0.05)$ compared to constant of elimination rate at terminal part of a reference (Sirdalud $®$ retard $6 \mathrm{mg}$ ). The AUC0-24 value was 1443.909 \pm 94.98 and1363.125 $\pm 101.32(\mu \mathrm{g} \cdot \mathrm{h} \mathrm{mL}-1)$ for the floating raft system (F9) and the market product, respectively. These results suggest increasing the absorption rate and extent by formulating the drug in sustained floating raft system, when compared to the obtained data of the market dosage form. The relative bioavailability of floating raft system (F9) calculated using the market dosage form (Sirdalud® retard $6 \mathrm{mg}$-tablet) as a reference was $103.54 \%$. The higher bioavailability of the floating raft system may be elucidated on the basis of higher viscosity of deacetylated gellan gum, Kollicoat ${ }^{\circledR}$ SR 30D and polymer and the formation of dense internal structure matrix, which enhances the ability of the raft system to encapsulate drug and decrease the loss of drug in the curing medium. As reported in the literature, utilizing floating raft system (FRS) has the feasibility of prolonging gastric residence time and the release rate of the drug.[27, 36] Moreover, increase of polymers concentration leads to enhance viscosity of the formulated raft systems and improve swelling characteristic of the polymer matrix. Consequently, the length of diffusion path increase as a result of swelling, reducing the dissolution medium and retarding the drug release.[27] The statistical analysis of logarithm values of $\mathrm{AUCO}-\infty$ and $\mathrm{Cmax}$ using one way ANOVA proved that statistical insignificant differences between the values of $\mathrm{AUCO}-\infty$ and Cmax were calculated for both examined formulae 


\section{CONCLUSION}

The present study showed capability of preparing floating raft systems by using mixtures of hydrophilic polymers with lipid polymer to extend the release of the tizanidine $\mathrm{HCl}$ for $12 \mathrm{~h}$. Moreover, the release of drug from the prepared raft system follows a Higuchi diffusion mechanism. Certain floating raft system (F9) showed enhanced bioavailability of tizanidine $\mathrm{HCl}$ when compared to the market dosage form Sirdalud® retard $6 \mathrm{mg}-$ tablet. Finally, the floating raft system can be a promising drug delivery system for sustaining the drug release and action.

\section{DISCLOSURE}

\section{The Authors Report No Conflicts Of Interest In} This Work.

\section{REFERENCES}

1. Mandal, U K, Chatterjee, B, and Senjoti, F G. "Gastro-retentive drug delivery systems and their in vivo success: A recent update." asian journal of pharmaceutical sciences 11 , no. 5 (2016): 575-584.

2. Mudie, D M, Amidon, G L, and Amidon, G E. "Physiological parameters for oral delivery and in vitro testing." Molecular pharmaceutics 7, no. 5 (2010): 1388-1405.

3. van Hoogevest, P, Liu, X, and Fahr, A. "Drug delivery strategies for poorly water-soluble drugs: the industrial perspective." Expert opinion on drug delivery 8, no. 11 (2011): 14811500.

4. Wang, X-q, Fan, J-m, Liu, Y-o, Zhao, B, et al. "Bioavailability and pharmacokinetics of sorafenib suspension, nanoparticles and nanomatrix for oral administration to rat." International journal of pharmaceutics 419 , no. 1-2 (2011): 339-346.

5. Razavi, M, Nyamathulla, S, Karimian, H, and Noordin, M I. "Novel swellable polymer of orchidaceae family for gastroretentive drug delivery of famotidine." Drug design, development and therapy 8 (2014): 1315.
6.

Kim, J S, Cha, K H, Kang, S Y, Won, D, et al. "In vivo gastric residence and gastroprotective effect of floating gastroretentive tablet of DA9601, an extract of Artemisia asiatica, in beagle dogs." Drug design, development and therapy 10 (2016): 1917.

7. Vyas, S P, Talwar, N, Karajgi, J S, and Jain, N K. "An erythrocyte based bioadhesive system for nasal delivery of propranolol." Journal of controlled release 23, no. 3 (1993): 231-237.

8. Berner, B and Louie-Helm, J, Tablet shapes to enhance gastric retention of swellable controlled-release oral dosage forms. 2002, Google Patents.

9. Arora, S, Ali, J, Ahuja, A, Khar, R K, and Baboota, S. "Floating drug delivery systems: a review." Aaps PharmSciTech 6, no. 3 (2005): E372-E390.

10. Prajapati, V D, Jani, G K, Khutliwala, T A, and Zala, B S. "Raft forming system-an upcoming approach of gastroretentive drug delivery system." Journal of controlled release 168, no. 2 (2013): 151-165.

11. Dongare, P S, Darekar, A B, Gondkar, S B, and Saudagar, R B. "Floating drug delivery system: A better approach." International Journal of Pharmacy and Biological Sciences 3, no. 4 (2013): 72-85.

12. Azim, A M A, El-Ashmoony, M, Swealem, A $\mathrm{M}$, and Shoukry, R A. "Transdermal films containing tizanidine: in vitro and in vivo evaluation." Journal of drug delivery science and technology 24, no. 1 (2014): 92-99.

13. Pendekal, $\mathrm{M} \mathrm{S}$ and Tegginamat, $\mathrm{P} \mathrm{K}$. "Formulation and evaluation of a bioadhesive patch for buccal delivery of tizanidine." Acta Pharmaceutica Sinica B 2, no. 3 (2012): 318324.

14. El-Mahrouk, G M, El-Gazayerly, O N, Aboelwafa, A A, and Taha, M S. "Chitosan lactate wafer as a platform for the buccal delivery of tizanidine $\mathrm{HCl}$ : in vitro and in vivo performance." International journal of pharmaceutics 467, no. 1-2 (2014): 100-112.

15. Chang, J Y, Oh, Y-K, Choi, H-g, Kim, Y B, and Kim, C-K. "Rheological evaluation of thermosensitive and mucoadhesive vaginal gels in physiological conditions." International journal of pharmaceutics 241, no. 1 (2002): 155-163.

16. Copetti, G, Grassi, M, Lapasin, R, and Pricl, S. "Synergistic gelation of xanthan gum with locust bean gum: a rheological investigation." Glycoconjugate journal 14, no. 8 (1997): 951961. 
17. Youssef, N A H A, Kassem, A A, El-Massik, M A E, and Boraie, $\mathrm{N}$ A. "Development of gastroretentive metronidazole floating raft system for targeting Helicobacter pylori." International journal of pharmaceutics 486 , no. 1 (2015): 297-305.

18. Ahmed, S M, Ali, A A, Ali, A M A, and Hassan, $\mathrm{O}$ A. "Design and in vitro/in vivo evaluation of sustained-release floating tablets of itopride hydrochloride." Drug design, development and therapy 10 (2016): 4061-4071

19. Masareddy, R, Kokate, A, and Shah, V. "Development of orodispersible tizanidine $\mathrm{HCl}$ tablets using spray dried coprocessed exipient bases." Indian J. Pharm. Sci 73, no. 4 (2011): 392.

20. Dash, S, Murthy, P N, Nath, L, and Chowdhury, P. "Kinetic modeling on drug release from controlled drug delivery systems." Acta Pol Pharm 67, no. 3 (2010): 217-23.

21. Patel, D M, Patel, N M, Pandya, N N, and Jogani, P D. "Gastroretentive drug delivery system of carbamazepine: formulation optimization using simplex lattice design: a technical note." AAPS PharmSciTech 8, no. 1 (2007): E82-E86.

22. Yang, X, Shah, S J, Wang, Z, Agrahari, V, et al. "Nanoparticle-based topical ophthalmic formulation for sustained release of stereoisomeric dipeptide prodrugs of ganciclovir." Drug delivery 23, no. 7 (2015): 2399-2409.

23. Iqbal, Z, Khan, R, Nasir, F, Khan, J A, et al. "Preparation and in-vitro in-vivo evaluation of sustained release matrix diclofenac sodium tablets using PVP-K90 and natural gums." Pak J Pharm Sci 24, no. 4 (2011): 435-443.

24. El-Mahrouk, G M, El-Gazayerly, O N, Aboelwafa, A A, and Taha, M S. "Chitosan lactate wafer as a platform for the buccal delivery of tizanidine $\mathrm{HCl}$ : in vitro and in vivo performance." International journal of pharmaceutics 467, no. 1 (2014): 100-112.

25. Siew, C K, Williams, P A, and Young, N W G. "New insights into the mechanism of gelation of alginate and pectin: charge annihilation and reversal mechanism." Biomacromolecules 6, no. 2 (2005): 963-969.

26. Rozier, A, Mazuel, C, Grove, J, and Plazonnet, B. "Gelrite ${ }^{\top}$ : A novel, ion-activated, in-situ gelling polymer for ophthalmic vehicles. Effect on bioavailability of timolol." International journal of pharmaceutics 57, no. 2 (1989): 163168.
27. El Nabarawi, M A, Teaima, M H, El-Monem, R A A, El Nabarawy, N A, and Gaber, D A. "Formulation, release characteristics, and bioavailability study of gastroretentive floating matrix tablet and floating raft system of Mebeverine HCl." Drug design, development and therapy 11 (2017): 1081.

28. Tang, J, Tung, M A, and Zeng, Y. "Gelling properties of gellan solutions containing monovalent and divalent cations." Journal of Food Science 62, no. 4 (1997): 688-712.

29. Rajinikanth, P S, Balasubramaniam, J, and Mishra, B. "Development and evaluation of a novel floating in situ gelling system of amoxicillin for eradication of Helicobacter pylori." International journal of pharmaceutics 335, no. 1 (2007): 114-122.

30. Kubo, W, Miyazaki, S, and Attwood, D. "Oral sustained delivery of paracetamol from in situgelling gellan and sodium alginate formulations." International journal of pharmaceutics 258, no. 1 (2003): 55-64.

31. Miyazaki, S, Kawasaki, N, Kubo, W, Endo, K, and Attwood, D. "Comparison of in situ gelling formulations for the oral delivery of cimetidine." International Journal of Pharmaceutics 220, no. 1 (2001): 161-168.

32. Ibrahim, H K. "A novel liquid effervescent floating delivery system for sustained drug delivery." Drug discoveries \& therapeutics 3, no. 4 (2009).

33. Shah, J C, Sadhale, Y, and Chilukuri, D M. "Cubic phase gels as drug delivery systems." Advanced drug delivery reviews 47, no. 2 (2001): 229-250.

34. Shah, J C, Sadhale, Y, and Chilukuri, D M. "Cubic phase gels as drug delivery systems." Advanced drug delivery reviews 47, no. 2-3 (2001): 229-250.

35. Rao, M R P and Shelar, S U. "Controlled release ion sensitive floating oral in situ gel of a prokinetic drug using gellan gum." Indian Journal of Pharmaceutical Education and Research 49 (2015): 158-167.

36. Youssef, N A H A, Kassem, A A, El-Massik, M $\mathrm{A}$ E, and Boraie, N A. "Development of gastroretentive metronidazole floating raft system for targeting Helicobacter pylori." International journal of pharmaceutics 486, no. 1-2 (2015): 297-305. 